Review

\title{
Putative Roles of Ouabainlike Compound in Hypertension: Revisited
}

\author{
Atsuo GOTO and Kaoru YAMADA*
}

\begin{abstract}
It is clear that defective renal sodium handling plays an important role in the development of hypertension and that this abnormality could be caused by heterogeneous hereditary factors in the kidney. It is likely that sodium pump inhibitors with or without whole-body autoregulation gradually produce a rise in blood pressure in response to retained body sodium. Accumulated evidence has suggested that several sodium pump inhibitors similar to cardiotonic steroids are present in the human body. Ouabainlike compound (OLC) has been found to be increased with high sodium intake and hypervolemia, and in essential hypertension, mineralocorticoid hypertension, and pregnancy-induced hypertension. Further, blocking the action of OLC with digibind or a novel anti-ouabain agent has been observed to lower blood pressure in several models of experimental and clinical hypertension. The blockade of OLC action may become the basis of novel rational antihypertensive agents and may help to solve the problems still present in the management of hypertensive patients. (Hypertens Res 2000; 23 Suppl: S7-S13)
\end{abstract}

Key Words: hypertension, sodium pump inhibitors, digitalislike factors, ouabain, sodium

\section{Renal Sodium Handling is Important in the Development of Hypertension}

Consistent with a large body of earlier work, recent findings using molecular techniques confirm the key role of the kidney in blood pressure (BP) variations in experimental and clinical studies (1). In knockout mice in which the natriuretic actions of dopamine, kallikreinkinin, or natriuretic peptides are defective because of the lack of $\mathrm{D}_{1 \mathrm{~A}}, \mathrm{~B}_{2}$, ANP-A receptors, or ANP itself, BP rises with or without high salt intake. A similar salt-sensitive hypertension is found in congenital kinin-deficient Brown-Norway-Katholiek rats (2). In clinical hypertension, the rise in BP in Liddle syndrome, glucocorticoidsuppressible aldosteronism, or the syndrome of apparent mineralocorticoid excess is closely related to constitutively increased sodium reabsorption resulting from distinct gene mutations (1). Another monogenic cause of human hypertension, mineralocorticoid receptor activation, has recently been reported (3).

Essential hypertension is a heterogeneous disease thought to be due to genetic and environmental factors that interact to increase BP. A recent long-term prospective study clearly demonstrated that a family history of hypertension in the donor determines the BP of the recipient of a kidney transplantation (4). This observation confirms the overriding role of the kidney in BP control and suggests that the human kidney harbors major hypertensive genetic mechanisms in essential hypertension (5). Only two genes, angiotensinogen and adducin, have met relatively stringent criteria supporting their role in the pathogenesis of essential hypertension. Both genes may act through a modification of renal tubular reabsorption. An alteration of the angiotensinogen gene, in addition to increasing BP through the vasoconstriction mediated by the vascular angiotensin II type $1\left(\mathrm{AT}_{1}\right)$ receptor, could increase sodium reabsorption, thereby augmenting

From the Department of Internal Medicine, Faculty of Medicine, University of Tokyo, Tokyo, Japan, and *Department of Human Health Care, Sanraku Hospital, Tokyo, Japan.

This study was supported by a grant from Uehara Memorial Foundation.

Address for Reprints: Atsuo Goto, M.D., Department of Internal Medicine, Faculty of Medicine, University of Tokyo, 7-3-1 Hongo, Bunkyo-ku, Tokyo 113-8655, Japan. 
the local formation of angiotensin II and activating adrenal $\mathrm{AT}_{1}$ receptors (1). An alteration of the adducin gene may lead to an increase in sodium pump activity due to either direct or secondary effects resulting from a primary stimulation of sodium transport across the luminal membrane, resulting in increases in tubular sodium reabsorption (6). Adducin polymorphisms in the human $\alpha$-subunit have actually been found to affect the relationship between renal sodium excretion and BP toward high saltsensitivity (7). It is readily apparent that the genes in which mutations may contribute to hypertension converge on a final common pathway, increased sodium reabsorption (decreased sodium excretion) in the kidney.

\section{Retained Sodium in the Body Somehow Leads to Hypertension}

Although numerous studies suggest that sodium retention and volume expansion cause a rise in BP not only in the states of mineralocorticoid excess or chronic renal failure but also in essential hypertension, the mechanisms involved are not certain $(8)$. A textbook on human physiology explains this mechanism as follows (9). "Think of the circulatory system as an elastic balloon filled with water. If a small amount of water is in the balloon, little pressure is exerted on the walls. As more water is added to the balloon, more pressure is exerted on the elastic walls. Therefore, if blood volume increases, BP increases; when blood volume decreases, BP decreases. If you fill a balloon close to the bursting point, you risk popping the balloon. The best way to reduce pressure is to remove some of the water." If the circulatory system is homogeneous, BP may be directly related to blood volume as explained in this textbook. However, the circulatory system consists of different components with distinct functions such as the arteries, capillaries, and veins. Further, $64 \%$ of blood volume exists in venous circulation and only $15 \%$ is present in arterial circulation. Since hypertension indicates high arterial pressure, it is rather difficult to explain the pathophysiology of hypertension without paying attention to venous circulation. Therefore, we believe the explanation in the textbook is oversimplified.

Guyton (10) has proposed that in dogs with reduced renal mass, volume expansion leads to whole-body autoregulation because hyperperfusion (the initial increase in cardiac output) causes locally induced vasoconstriction in the systemic arterial resistance vessels. According to this theory, the myogenic response to hyperperfusion in the arterial resistance vessels explains the salt-induced increase in BP. However, all parts of the circulatory system are actually affected in essential hypertension. The systemic veins exhibit increased tone and have a reduced distensibility or compliance (11). The pulmonary arteries exhibit augmented reactivity to vasoconstrictors. Furthermore, involvement of the heart and veins may be critical in the process by which salt produces hypertension, by precluding simple compensatory redistribution of abnormal fluid volumes (12). Thus, elevated arterial resistance, in the absence of enhanced ventricular performance and decreased venous compliance, would simply decrease cardiac output and move blood volume from the arterial to the venous side of the circulation. We believe that the hypothesis of resistance-vessel autoregulation cannot account for the reduced venous compliance or the increased tone in capacitance arteries.

The ways in which changes in sodium status can influence arterial vascular resistance may be well accounted for by some humoral factor(s) inducing total changes in the circulatory system, including low-pressure components (13-15). The endogenous digitalislike factor (EDLF) could be a good candidate for this humoral factor. In fact, it has been reported by Pamnani, Overbeck, and Clough that the ouabain-sensitive $\mathrm{Rb}$ uptake is diminished in the veins of dogs with one-kidney perinephritic hypertension, and that the $\mathrm{Na}^{+}, \mathrm{K}^{+}$-ATPase activity of myocardial microsomes is suppressed in the right ventricles of rats with one-kidney, one-clip hypertension (16).

According to the EDLF theory, it is generally thought that salt retention and plasma-volume expansion trigger the secretion of EDLF, the purpose of which is the restoration of extracellular fluid volume via natriuresis. Increased secretion of EDLF may lead to the elevated cytosolic $\mathrm{Ca}^{2+}$ and vasoconstriction that is responsible for the development and perpetuation of hypertension (13-15). Although numerous findings support the potential role of EDLF in the physiological control of sodium homeostasis, the exact trigger promoting EDLF secretion and the natriuretic action of EDLF still remains to be clarified.

\section{Endogenous Digitalislike Factor(s) Are Present in the Body}

Plasma membrane $\mathrm{H}^{+}$-ATPase and $\mathrm{Na}^{+}, \mathrm{K}^{+}$-ATPase belong to the subfamily of ion pumps that have been termed P2-ATPases. The former is present in plants, fungi, protozoa, and archaea. This wide distribution among species suggests that $\mathrm{P}$-type $\mathrm{H}^{+}$-ATPases appeared very early in evolution. In contrast, $\mathrm{Na}^{+}, \mathrm{K}^{+}$-ATPases probably appeared late in evolution because they were restricted to animals, who evolved in the sea and were dependent on systems to extrude sodium. Three lines of evidence (Table 1) support the existence of EDLF in animals $(17,18)$.

A strong body of evidence suggests that a major biologically active EDLF from human circulation and the bovine hypothalamus is ouabainlike compound (OLC) (19-21). OLC has also been found in human urine, neonatal cord blood, and cultured PC12 cells and has been regarded so far as the most appealing of candidate substances. The purified OLC structure has been under 
Table 1. Evidence for the Presence of Endogenous Digitalislike Factor

Conservation of high affinity ouabain binding site on $\mathrm{Na}^{+}, \mathrm{K}^{+}-\mathrm{ATPase} \alpha$ chain

Unaltered kinetic behavior of $\mathrm{Na}^{+}, \mathrm{K}^{+}$-ATPase with site-specific mutagenesis conferring ouabain resistance

Presence of specific ouabain-binding globulin

Table 2. Evidence for the Contribution of Ouabainlike Compound to Hypertension

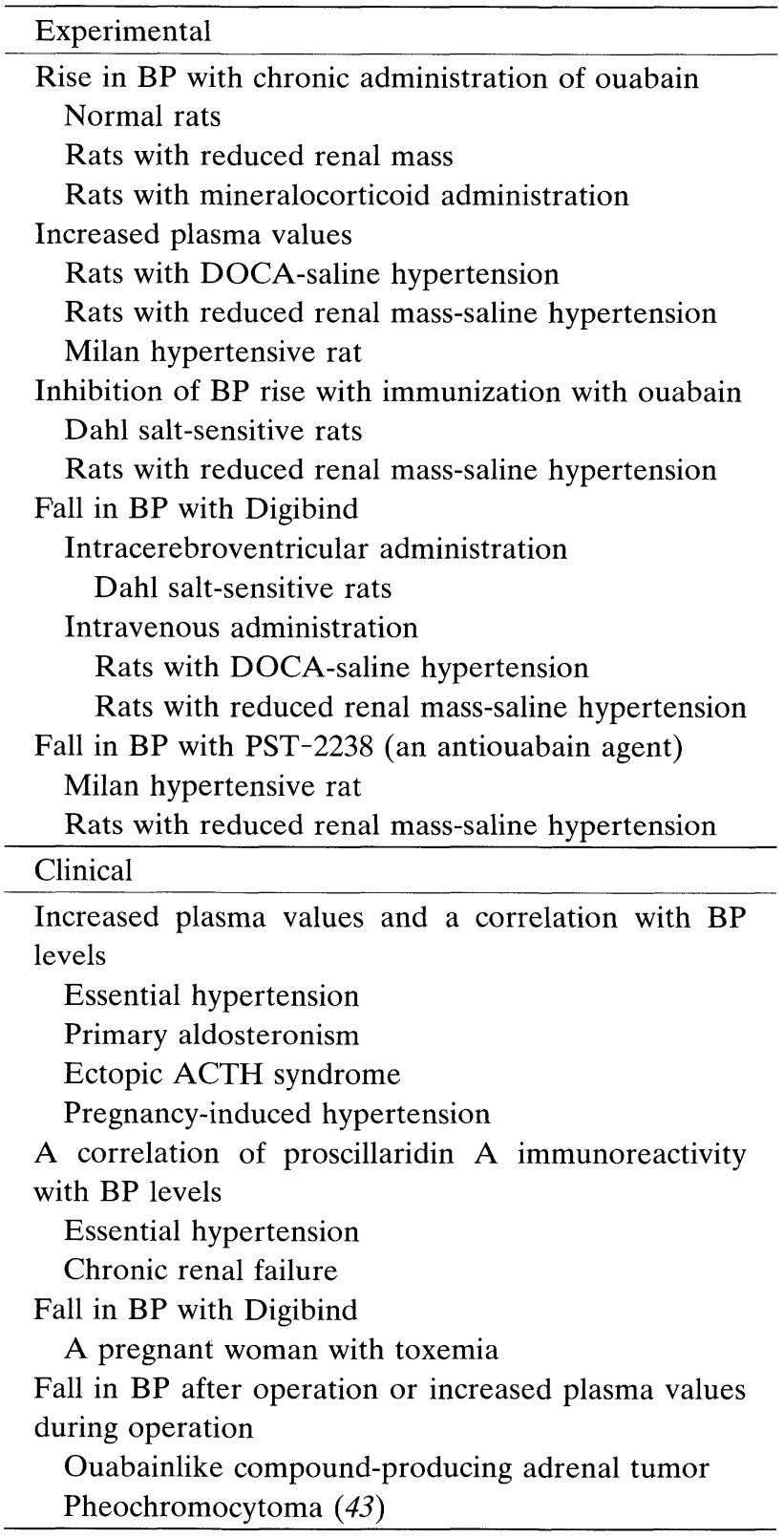

intensive investigation and has turned out to be ouabain itself and not an ouabain isomer (22). However, the possibility that endogenous "ouabain" is slightly different from plant ouabain cannot completely be excluded.
There is still growing evidence of other potential EDLFs structurally related or unrelated to ouabain such as dihydroouabain, digoxinlike, proscillaridin A-like, marinobufageninlike, and bufalinlike substances (23-25). Therefore, observed OLC concentrations based on RIA for ouabain may represent only a portion of bioactive EDLF molecules in the circulation.

\section{Pathogenetic Roles of Ouabainlike Compound in Hypertension}

Accumulating evidence points to the important role of OLC in BP regulation (Table 2). In previous studies, ouabain injected once a week for 6 weeks or a continuous infusion of ouabain for up to 6 days has failed to increase the BP of rats. In contrast, chronic administration of ouabain gradually leads to the development of hypertension in rats (26). This hypertensinogenic action of ouabain is amplified by reduced renal mass and the co-administration of mineralocorticoid. It is a reasonable assumption that under these circumstances the hypertensive effect of ouabain manifests itself due to the absence of its natriuretic action.

Elevated OLC levels are found in the plasma of rats with DOCA-saline hypertension and reduced renal masssaline hypertension and Milan hypertensive rats (27). Recent studies with rats immunized against ouabain have resulted in a partial inhibition of reduced renal mass-saline hypertension and sodium-induced hypertension in Dahl salt-sensitive (S) rats $(28,29)$. Digibind capable of blocking OLC action has been found to produce a slowly progressive and well-maintained BP fall in DOCA-saline hypertension and reduced renal mass-saline hypertension $1 \mathrm{~h}$ after the intravenous injection $(30,31)$. Digibind has been administered intracerebroventricularly in Dahl S rats on a high sodium diet, resulting in a significant decrease in BP $18 \mathrm{~h}$ after the injection, reaching values for Dahl S rats on a regular sodium diet (32).

In clinical studies, higher plasma levels of OLC have been found in patients with two types of mineralocorticoid hypertension: primary aldosteronism and ectopic corticotrophin syndrome $(33,34)$. Plasma levels of OLC are also higher in $30-45 \%$ of patients with essential hypertension, with multiple regression analysis showing a significant relationship between mean BP and plasma OLC (33). Furthermore, the levels of proscillaridin A immunoreactive substance inhibiting the sodium pump of human erythrocytes and coeluting with ouabain on HPLC 

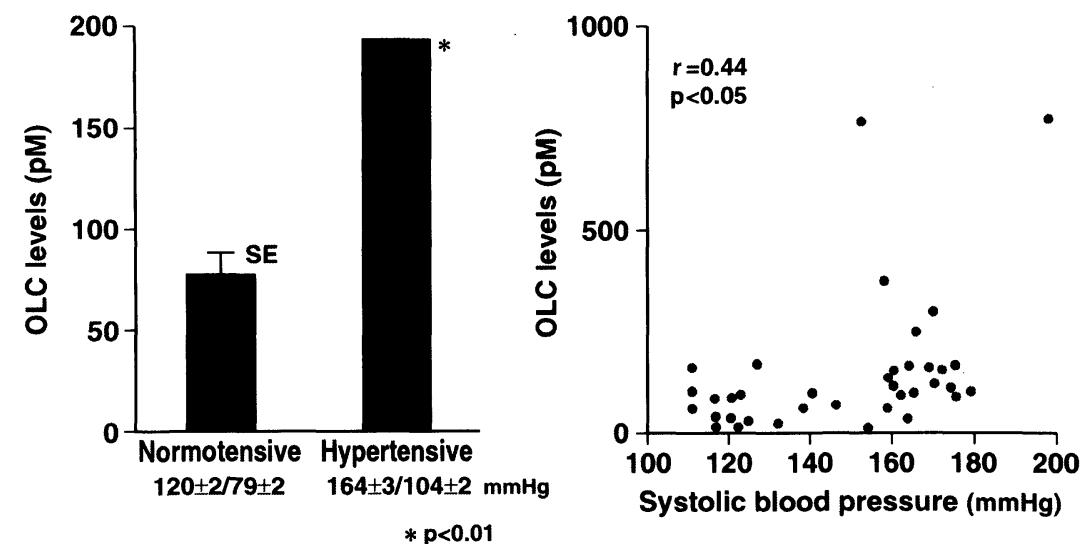

Fig. 1. Plasma values of ouabainlike compound $(O L C)$ in normotensive subjects and patients with essential hypertension (left). The relation between OLC values and systolic blood pressure levels (right) in both groups.
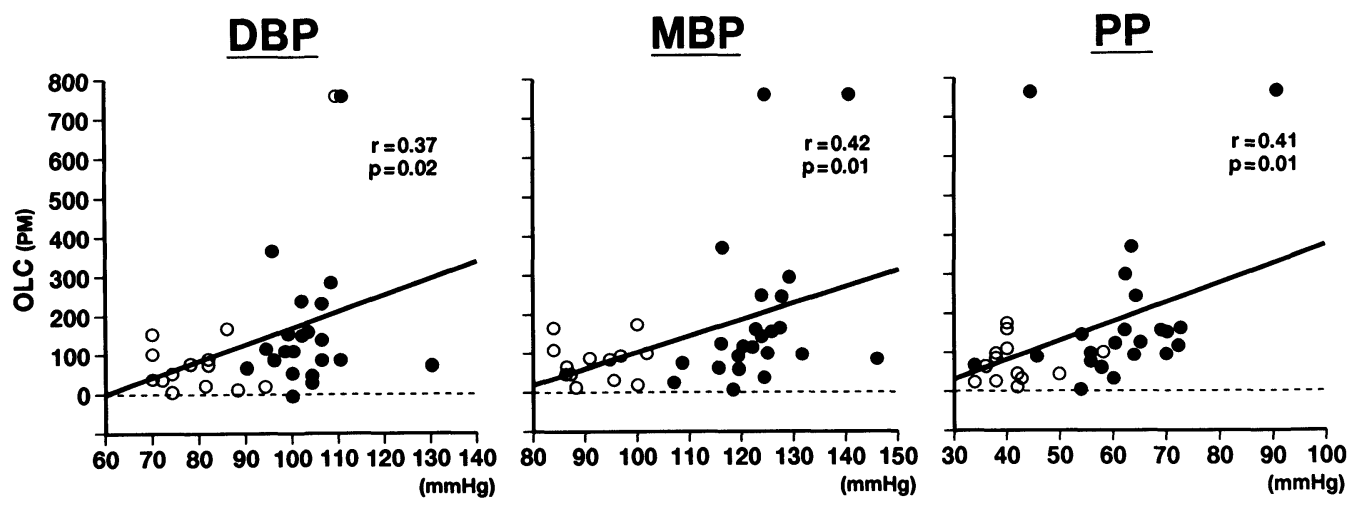

Fig. 2. The relations between plasma values of ouabainlike compound (OLC) and diastolic blood pressure (DBP, left), mean blood pressure (MBP, middle), and pulse pressure (PP, right) levels in normotensive subjects (open circle) and patients with essential hypertension (closed circle).

correlate with mean BP in humans with normotension, hypertension, and chronic renal failure (25). Substantial increases in plasma OLC and marinobufagenin immunoreactivity have been demonstrated in patients with preeclamptic hypertension (35).

In our study (Fig. 1), we found a significant increase in OLC levels in 25 patients with essential hypertension (age $51 \pm 2$, BP $164 \pm 3 / 104 \pm 2 \mathrm{mmHg}$, OLC $194 \pm 39 \mathrm{pM}$ ), as compared with 14 normotensive subjects (age $33 \pm 3$, BP $120 \pm 2 / 79 \pm 2 \mathrm{mmHg}$, OLC $76 \pm 13 \mathrm{pM}, p<0.01)$. Plasma OLC was measured by radioimmunoassay as reported previously (34). OLC levels correlated with systolic BP values (Fig. 1) as well as with other BP parameters such as diastolic BP, mean BP, and pulse pressure in all patients (Fig. 2).

These findings strongly support the notion that OLC may play a role in several types of hypertension. Blocking the action of OLC may become the basis of a new rationale to design novel antihypertensive agents. $17 \beta-(3-$ furyl)-5 $\beta$-androstane- $3 \beta, 14 \beta, 17 \alpha$-triol (PST-2238) has been observed to reduce in a dose-dependent manner the development of hypertension in ouabain-induced hypertensive rats and Milan hypertensive rats. As mentioned above, OLC has been demonstrated to be present in greater amounts in the hypothalamus, hypophysis, and plasma of Milan hypertensive rats than in those of Milan normotensive rats $(36,37)$. In our preliminary two experiments, PST-2238 also significantly reduced BP in reduced renal mass-saline hypertension, in which plasma OLC levels are substantially increased, as confirmed in our previous study (our unpublished observation, 1999).

Many investigators still doubt the physiological or pathophysiological roles of OLC, primarily because of the discrepancies between the observed OLC concentrations and the effective digoxin concentrations used for heart failure patients in clinical practice or the huge amounts of 


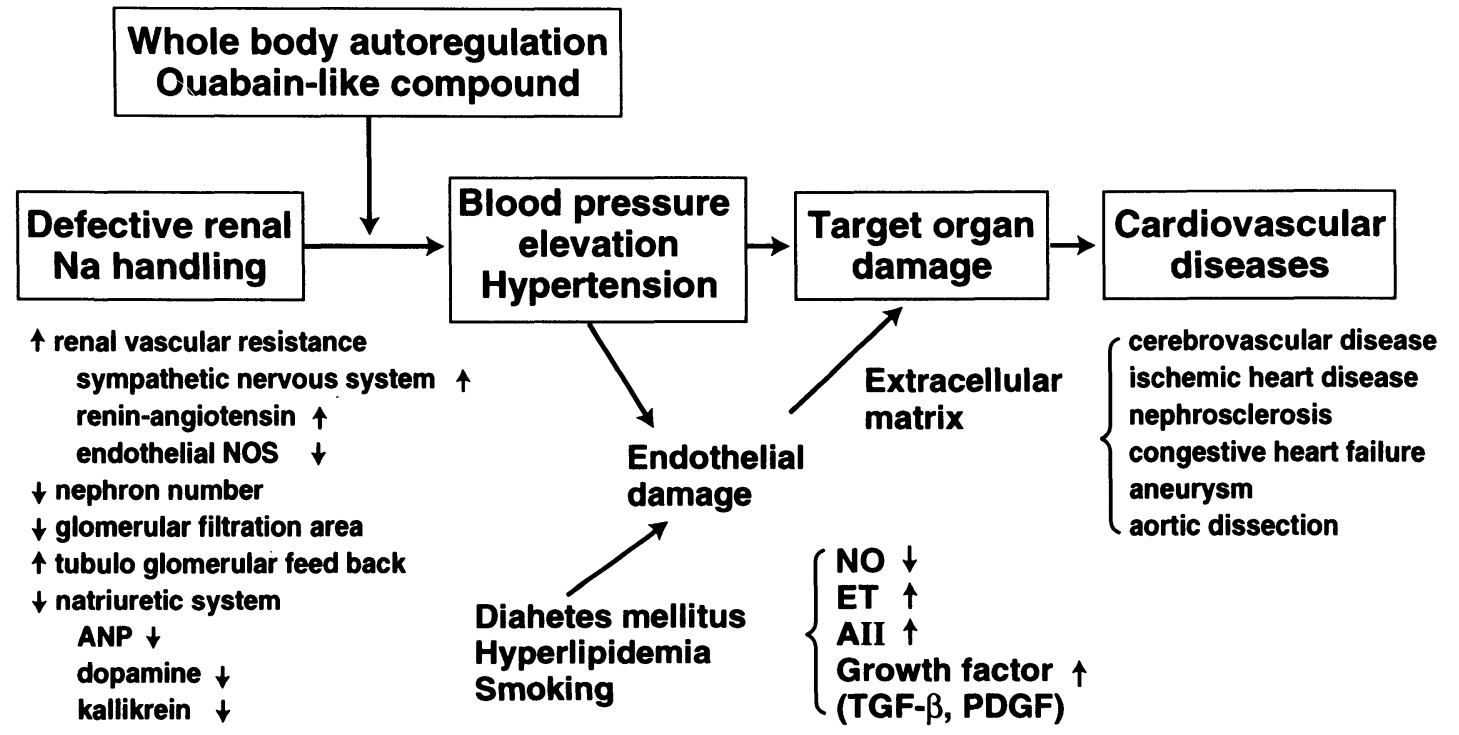

Fig. 3. Putative roles of ouabainlike compound in the development and pathophysiology of essential hypertension.

$\mathrm{Na}^{+}, \mathrm{K}^{+}$-ATPase in the body, especially in skeletal muscles. However, cardiotonic steroids may elicit their actions at much lower concentrations than previously believed. Nanomolar concentrations of ouabain increase cytosolic free $\mathrm{Ca}^{2+}$ concentrations and the amount of $\mathrm{Ca}^{2+}$ stored in the sarcoplasmic reticulum, and can augment caffeine-induced contractions in the presence of moderate sympathetic stimulation in rat vascular smooth muscle (38). Nanomolar concentrations of ouabain may directly increase $\mathrm{Ca}^{2+}$ influx, and the mechanisms underlying the $\mathrm{Ca}^{2+}$ influx could be different from those operating with higher concentrations of ouabain. This interpretation is supported by a recent finding by Juhaszova and Blaustein (39), who have observed that the $\alpha_{1}$ isoform is ubiquitously distributed over the surfaces in the plasma membrane of rat astrocytes and arterial myocytes, but that the $\alpha_{2} / \alpha_{3}$ isoform is confined to a reticular distribution within the plasma membrane that parallels underlying endoplasmic or sarcoplasmic reticulum and colocalizes with the $\mathrm{Na}^{+}-\mathrm{Ca}^{2+}$ exchanger. Thus $\alpha_{1}$ may regulate bulk cytosolic sodium, whereas $\alpha_{2} / \alpha_{3}$ may regulate sodium and, indirectly, $\mathrm{Ca}^{2+}$ in a restricted cytosolic space and modulate reticulum $\mathrm{Ca}^{2+}$ content and $\mathrm{Ca}^{2+}$ signaling. Recent findings indicate that nanomolar concentrations of ouabain inhibit rat vascular muscle $\mathrm{Na}^{+}$, $\mathrm{K}^{+}$-ATPases other than $\alpha_{1}$, which is involved in the response to endothelium-derived hyperpolarizing factor, and enhance the reactivity to phenylephrine $(40,41)$.

\section{Future Perspectives}

Arterial hypertension is a risk factor for many cardiovascular diseases (Fig. 3). The basis of these car- diovascular diseases is target organ damage, and they are characterized by endothelial damage induced by high BP and other risk factors such as diabetes, hyperlipidemia, and smoking. Many hypertensive persons sustain vascular damage before they receive adequate treatment. Therefore, treating this already manifest hypertension will not prevent all the hypertension-related cardiovascular disease. Cardiac and renal complications with an incidence above the level found in the normal population may persist in patients, despite a good control of their hypertension. Several studies have repeatedly demonstrated the failure of therapy to reduce the risk of cardiovascular disease in relation to that seen in untreated persons with similar BP levels.

Taking the above into consideration, the search for more specific and rational antihypertensive agents should be continued. There is no doubt that defective renal sodium handling plays an important role in the development of hypertension, and that this abnormality in the kidney could be based on various causes, as shown in Fig. 3. It is likely that OLC, with or without whole-body autoregulation, gradually produces a rise in $\mathrm{BP}$ in response to retained body sodium. Therefore, a blockade of OLC action may become the basis of novel rational antihypertensive agents (42). Because it has been reported that plasma OLC levels are higher in a majority of patients with essential hypertension, there are clinically important implications as to whether orally administered PST 2238, the prototype antiouabain agent, may exert an antihypertensive action in human hypertension. 


\section{References}

1. Lifton RP: Molecular genetics of human blood pressure variation. Science 1996; 272; 676-680.

2. Majima M, Katori S: Approaches to the development of novel antihypertensive drugs: crucial role of the renal kallikrein-kinin system. Trends Pharmacol Sci 1995; 16: 239-245.

3. Geller DS, Farhi A, Moritz M, Spitzer A, Lifton RP: A new Mendelian form of human hypertension caused by an activating mutation in the mineralocorticoid receptor. J Am Soc Nephrol 1999; 10: 345A.

4. Guide E, Menghetti D, Milani S, et al: Hypertension may be transplanted with the kidney in humans: a longterm historical prospective follow-up of recipients grafted with kidney coming from donors with or without hypertension in their families. J Am Soc Nephrol 1996; 7: 1131-1138.

5. Woolfson RG, de Wardener HE: Primary renal abnormalities in hereditary hypertension. Kidney Int 1996; 50: 717-731.

6. Cusi D, Barlassina C, Azzani T, et al: Polymorphisms of $\alpha$-adducin and salt sensitivity in patients with essential hypertension. Lancet 1997; 349: 1353-1359.

7. Manunta P, Cusi D, Barlassina C, et al: $\alpha$-Adducin polymorphisms and renal sodium handling in essential hypertension. Kidney Int 1998; 53: 1471-1478.

8. Cowley AW: Long-term control of arterial blood pressure. Physiol Rev 1992; 72: 231-300.

9. Silverthorn DU: Blood flow and the control of blood pressure, in Silverthorn DU(ed): Human Physiology. New Jersey, Prentice Hall, 1998, pp 423-452.

10. Guyton AC: Blood pressure control - special role of the kidneys and body fluids. Science 1991; 252: 18131816.

11. Blaustein MP, Hamlyn JM: Pathogenesis of essential hypertension: a link between dietary salt and high blood pressure. Hypertension 1991; 18: III-184-III-195.

12. Overbeck HW: Salt and essential hypertension, in Edwards CRW, Carey RM (eds): Essential Hypertension as an Endocrine Disease. London, Butterworths, 1985, pp 97-131.

13. Haddy FJ, Overbeck HW: The role of humoral agents in volume expanded hypertension. Life Sci 1976; 19: 935948.

14. De Wardener HE, MacGregor GA: Dahl's hypothesis that a saluretic substance may be responsible for a sustained rise in arterial pressure: its possible role in essential hypertension. Kidney Int 1980; 18: 1-9.

15. Blaustein MP: Physiological effects of endogenous ouabain: control of intracellular $\mathrm{Ca}^{2+}$ stores and cell responsiveness. Am J Physiol 1993; 264: C1367-C1387.

16. Haddy FJ, Pamnani MB: Role of ouabain-like factors and Na-K-ATPase inhibitors in hypertension: some old and recent findings. Clin Exp Hypertens 1998; 20: 499508.

17. Goto A, Yamada K, Yagi N, et al: Physiology and pharmacology of endogenous digitalis-like factors. Pharmacol
Rev 1992; 44: 377-399.

18. Goto A, Yamada K: Ouabain-like factor. Curr Opin Nephrol Hypertens 1998; 7: 189-196.

19. Hamlyn JM, Blaustein MP, Bova S, et al: Identification and characterization of a ouabain-like compound from human plasma. Proc Natl Acad Sci USA 1991; 88: 62596263.

20. Tymiak AA, Norman JA, Bolger M, et al: Physicochemical characterization of an ouabain isomer isolated from bovine hypothalamus. Proc Natl Acad Sci USA 1993; 90: 8189-8193.

21. Zhao N, Lo L-C, Berova $\mathrm{N}$, et al: Na,K-ATPase inhibitors from bovine hypothalamus and human plasma are different from ouabain: nanogram scale CD structural analysis. Biochemistry 1995; 34: 9893-9896.

22. Kawamura A, Guo J, Itagaki Y, et al: On the structure of endogenous ouabain. Proc Natl Acad Sci USA 1999; 96: $6654-6659$.

23. Samuelov S, Lichtstein D: Digitalis-like compounds and $\mathrm{Na}^{+}, \mathrm{K}$-ATPase activity in bovine lens. Pflügers Arch 1997; 433: 435-441.

24. Tao Q-F, Hollenberg NK, Price AP, Graves SW: Sodium pump isoform specificity for the digitalis-like factor isolated from human peritoneal dialysate. Hypertension 1996; 29: 815-821.

25. Sich B, Kirch U, Tepel M, et al: Pulse pressure correlates in humans with a proscillaridin: a immunoreactive compound. Hypertension 1996; 27: 1073-1078.

26. Manunta P, Rogowski AC, Hamilton BP, et al: Ouabain induced hypertension in the rat: relationships among plasma and tissue ouabain and blood pressure. J Hypertens 1994; 12: 569-576.

27. Yamada K, Goto A, Chen H, et al: Role of ouabainlike compound in rats with reduced renal mass-saline hypertension. Am J Physiol 1994; 266: H1357-H1362.

28. Yamada K, Goto A, Nagoshi $\mathrm{H}$, et al: Participation of ouabainlike compound in reduced renal mass-saline hypertension. Hypertension 1994; 23: I110-I113.

29. Gomez-Sanchez EP, Gomez-Sanchez CE, Fort C: Immunization of Dahl SS/jr with an ouabain conjugate mitigates hypertension. Am J Hypertens 1994; 7: 591596.

30. Tao Q-F, Soszynski PA, Hollenberg NK, et al: Specificity of the volume-sensitive sodium pump inhibitor isolated from human peritoneal dialysate in chronic renal failure. Kidney Int 1996; 49: 420-429.

31. Kaide J, Ura N, Torii T, et al: Effects of digoxin-specific antibody Fab fragment (Digibind) on blood pressure and renal water-sodium metabolism in $5 / 6$ reduced renal mass hypertensive rats. Am J Hypertens 1999; 12: 611619.

32. Huang BS, Leenen F: Brain ouabain mediates the sympathoexcitatory and hypertensive effects of high sodium intake in Dahl salt-sensitive rats. Circ Res 1994; 74: 586595.

33. Rossi G, Manunta P, Hamlyn JM, et al: Immunoreactive endogenous ouabain in primary aldosteronism and essential hypertension: relationships with plasma renin, aldosterone and blood pressure levels. J Hypertens 1995; 13: 1181-1192. 
34. Goto A, Yamada K, Hazama H, et al: Ouabainlike compound in hypertension associated with ectopic corticotrophin syndrome. Hypertension 1996; 28: 421-425.

35. Lopatin DA, Ailamazian EK, Dmitrieva RI, et al: Circulating bufodienolide and cardenolide sodium pump inhibitors in preeclampsia. J Hypertens 1999; 17: 11791187.

36. Ferrari P, Torielli L, Ferrandi M, et al: PST 2238: a new antihypertensive compound that antagonizes the longterm pressor effect of ouabain. J Pharmacol Exp Ther 1998; 285: 83-94.

37. Ferrari P, Ferrandi M, Tripodi G, et al: PST 2238: a new antihypertensive compound that modulates $\mathrm{Na}, \mathrm{K}$ ATPase in genetic hypertension. $J$ Pharmacol Exp Ther 1999; 288: 1074-1083.

38. Zhu Z, Tepel M, Neusser M, et al: Low concentrations of ouabain increase cytosolic free calcium concentration in rat vascular smooth muscle cells. Clin Sci 1996; 90: 912.

39. Juhaszova $\mathrm{M}$, Blaustein, $\mathrm{MP}: \mathrm{Na}^{+}$pump low and high ouabain affinity $\alpha$ subunit isoforms are differently distributed in cells. Proc Natl Acad Sci USA 1997; 94: 18001805 .

40. Edwards G, Gardener MJ, Feletou M, et al: Further investigation of endothelium-derived hyperpolarizing factor (EDHF) in rat hepatic artery: studies using 1-EBIO and ouabain. Br J Pharmacol 1999; 128: 1064-1070.

41. Rossoni LV, Cunha V, Franca A, et al: The influence of nanomolar ouabain on vascular pressor responses is modulated by the endothelium. J Cardiovasc Pharmacol 1999; 34: 887-892.

42. Goto A, Yamada K: An approach to the development of novel antihypertensive drugs: potential role of sodium pump inhibitor. Trends Pharmacol Sci 1998; 19: 201204.

43. Komiyama Y, Nishimura N, Munakata M, et al: Increases in plasma ouabainlike immunoreactivity during surgical extirpation of pheochromocytoma. Hypertens Res 1999; 22: 135-139. 